\title{
Analysis of the building shape erected in Krakow and its impact on construction costs
}

\author{
Krzysztof Zima \\ Section of Technology and Building \\ Management, Cracow University of \\ Technology, Krakow, Poland. \\ e-mail: kzima@izwbit.pk.edu.pl
}

\author{
Edyta Plebankiewicz \\ Section of Technology and Building \\ Management, Cracow University of \\ Technology, Krakow, Poland \\ e-mail: eplebank@izwbit.pk.edu.pl
}

DOI 10.5592/otmcj.2012.1.6 Research paper

Keywords
Cost of building, building
shape, multifamily
buildings

\section{Introduction}

The choice of a particular architectural solution when designing a building considerably influences the costs of its construction (Ferry and Brandon, 2007). Generally speaking, the more complex the form of the horizontal projection is, the greater expenditures for the construction must be paid. One of the reasons is the fact that the shape of the building influences significantly the number of such construction elements as foundations, walls, ceilings or the roof (Ashworth, 2004).

The article presents the basic methods of evaluating the degree of complexity of the building shape. On the basis of factors specifying building shape complexity an analysis of multi-family buildings in Krakow was conducted. The analysis concerned 40 buildings constructed by developers who received their building permit in the years 2004-2005, and 30 buildings whose building permit was issued in the second half of the year 2010. The aim of the article is to assess the degree of building shape complexity of Krakow's buildings and to compare the changes in building design which could be observed during the recent years. The study also included the way the grounds were used for the analysed constructions. 


\section{Methods of evaluating the degree of building complexity}

The evaluation of the building's construction costs at the design stage has a decisive influence on the decisions made at subsequent stages. In literature one may find a number of factors deciding on the construction costs. Kouskoulas and Koehn (1974) identified the following independent variables specifying the costs of constructing a building: location, year of construction, building type, building height, building quality and construction technology. Brandon (1978) proposed using a building shape index, the number of storeys, the inner division of the building area coefficient, the average height of the storey, the coefficient specifying the percentage of the glass area and the compactness of the block. Karshenas (1984) added one more factor to these given by Brandon, namely the area of the construction site. Swaffield and Pasquire (1996) suggested the following: the percentage of the glass area, the length of the building perimeter, the building's total height, the volume measure of the rooms and technical corridors, the volume measure of the area used up by heating systems, ventilation and air conditioning. Sonmez (2004) in his regression model describing the key factors influencing building shape included: construction timing, locations, the area of the construction site, the percentage of the shared areas, the total area, and the number of storeys. It is worth noting that these studies, except Kouskoulas and Koehn's research, consider building shape and its derivatives, such as building perimeter and the construction site area, as key factors influencing the costs of constructing a building. Evaluation of the degree of building shape complexity is, therefore, a crucial decision element which significantly influences the costs of construction and the cost of building use.
Outer partitions, both vertical and horizontal, are relatively expensive elements of the building. Outer walls include in their costs the supporting walls and curtain walls, plumb lines, insulation, outer facing and inner veneer.

The conclusion is that the smaller the surface of the building and the more compact the block of the building is, the more advantageous the layout of the building is, as far as construction costs are concerned. A general rule says that the simpler the building shape is, the lower the unit costs are (Selley, 1983). A building of a simple shape has fewer outer walls surrounding the floor area and a smaller number of ceilings. Building shape has, then, a great influence on the total costs of construction. This effect concerns not only the outer but also the inner loadbearing walls and partition walls. The layout of these walls often depends on the layout of the outer supporting walls. The improved layout of the building block makes it possible to improve the layout of flats and corridors. This should also enhance the relation between the living area and the communication area. Thus one can assume that a square- or rectangle-shaped building has the best building layout coefficient (Staedman et al., 2009; Wing, 1999).

Therefore one may ask whether the shape and size of the building influence energy efficiency. A building loses the most of heat through walls and roof, so the less complex its shape and the more compact its block are, the lower the heat loss is (fewer thermal bridges and, generally, smaller contact area with the surroundings) (Zima, 2008). Consequently, an energy efficient building should be designed on the plan of the square or a not very elongated rectangle. It is crucial that the relation between the outer partitions surface and the building projec- tion surface or its cubic capacity is as small as possible, so when designing a low-cost building one should avoid cross-, letter-L-, letter-T- or letter- $\mathrm{H}$ shaped buildings.

Then how the complexity (or simplicity) of building shape should be measured? The coefficient specifying the layout of the building should consist of variables which have a significant influence on construction costs and are known already at the concept stage. Such variables may include, for example, the above mentioned key factors influencing building costs: building perimeter and the surface of the building projection. Other factors connected with building shape which influence building costs, that is the number of right angles, the length of the longer side of the building perimeter, the sum of all inner angles, etc. are of a slightly lesser importance.

It is necessary to observe that the bulk of the research into this issue presents sophisticated methods of evaluating a building's construction costs which take into consideration not only the shape but also other factors, which are not included in the present discussion. These methods are based on a complicated mathematical apparatus and are hard to apply. Therefore, for the estimation of building shapes the authors use the factors proposed by Brandon (1978) and Kouskoulas and Koehn (1974).

The example coefficients specifying the complexity (or simplicity) of building shape include:

1. W/F (Wall to Floor) index

2. LBI (Length/Breadth Index) index

3. PSI (Plan/Shape Index) index

4. Cook's JC (Cooke's JC shape efficiency) index

5. POP (Perimeter Over Plan) index

6. building planning “ $\mathrm{m}$ " index

7. VOLM (Volume - block compactness) index

8. Optimum envelope area 
The W/F index (Brandon, 1978)

The W/F index (Wall/Floor Ratio) specifies the ratio between the wall surface and floor surface. It is assumed that the smaller the index's value is, the lower the construction costs will be. The shape generating the smallest cost is the square, for which the index's value is 0 . The W/F index is expressed by the following formula:

$$
\frac{W}{F}=\frac{L-L_{s}}{L_{c}} \cdot 100 \%
$$

where: $\mathrm{L}$ - building perimeter calculated from the contour of the outer walls, Ls - perimeter of the square of the same surface as the building being compared.

\section{The LBI index (Brandon, 1978)}

The LBI index (the Length/Breadth Index) assumes that every shape of the building projection is reduced to a rectangle with the same surface and perimeter. For a square the factor has value 1 . The greater the value is, the more complex shape the building will have. The LBI index is expressed by the following formula:

$$
L B I=\frac{L+\sqrt{L^{2}-16 F}}{L-\sqrt{L^{2}-16 F}}
$$

where: $\mathrm{L}$ - building perimeter calculated from the contour of the outer walls, $\mathrm{F}$ - the surface of the building projection.

The PSI index (Brandon, 1978) The PSI index (Plan/Shape Index) is a development of the LBI index and is expressed by the following formula:

$$
P S I=\frac{G+\sqrt{G^{2}-16 R}}{G-\sqrt{L^{2}-16 R}}
$$

where: $\mathrm{G}$ - the sum of outer perimeters of each floor divided by the number of floors, $\mathrm{R}$ - the gross surface divided by the number of floors.
The Cook's JC shape effectiveness index (Kouskoulas and Koehn, 1974)

The JC index uses the relation between the perimeter and the surface of the building, and is expressed in the following way:

$$
J C=\frac{L}{4 \sqrt{F}}-1
$$

where: $L$ - building perimeter calculated from the contour of the outer walls, $\mathrm{F}$ - the surface of the building projection.

The POP (plan compactness ratio) index (Brandon, 1978)

In this method the point of reference is the shape of the circle, which has the smallest ratio between the circumference and the surface of the building. For the circle the POP factor is 1 . The lower the index's value is the more complex the building shape will be. The POP index is depicted by the following formula:

$$
\mathrm{POP}=\frac{2 \sqrt{\pi \cdot F}}{L}
$$

The building planning " $\mathrm{m}$ " index (Kouskoulas and Koehn, 1974)

Since the results of using the various methods employing the ratio between the building perimeter calculated from the contour of its outer walls (L) and the surface of the building projection (F) are similar, the methods can be simplified by using this formula:

$$
m=\frac{L}{\sqrt{F}}
$$

The " $m$ " index may take the following values:

$-m=3.54-$ for a circle

$-m=(3.54 ; 4)-$ for elliptical shapes

$-m=4-$ for a square

$-m>4$ - the remaining rectangular and other shapes.
Considering technology and realization costs it is assumed that the most economical solutions take the index approximating (but not smaller than) 4.

\section{VOLM (block compactness) index} (Brandon, 1978)

In the case of this index the point of reference is the shape of a hemisphere. When specifying the block compactness of a building one takes into consideration three dimensions of the object. The VOLM index is depicted by this formula:

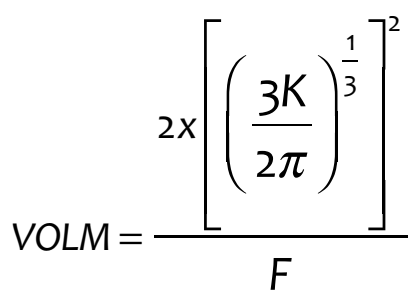

where: $\mathrm{K}$ - the volume measure of the building, F - the surface of the building projection.

Outer walls (their number is specified in the formulas above by L) are a costly element, so each change in the shape of the building causing the increase in the number of outer walls per the building projection surface unit $F$ will cause the increase of construction costs. The higher the value of the indexes specified in 1), 2), 3) and 5) and the lower for formula 4 ), the greater the complexity of the shape of a building and so are the construction costs. In the case of the VOLM index, the authors assumed a cube as an optimal solution, thus the optimal value of the block compactness coefficient is 3.84 , which constitutes a nominal value one should strive for. All the values taken by the block compactness coefficient higher or lower than 3.84 indicate a greater complexity of the block. 


\section{Evaluation of residential investments undertaken in Krakow}

The study concerned 40 multi-family buildings constructed by developers in Krakow for whom building permits were granted in 2004-2005, and - for comparison - 30 multi-family buildings for which building permits were given in the second half of the year 2010. The study used the records from the Office of the City of Krakow, Faculty of Architecture and Urban Planning. The authors analysed the degree of building shape complexity employing the formulas described above, and the way the grounds were used.

\section{Description of the investments with building permits issued in} 2004-2005

The analysis concerns 40 multifamily buildings constructed in Krakow, which received building permits in 2004-2005. The distribution of the survey sample grouped according to the number of the above-ground storeys is presented in Table 1.

\begin{tabular}{|c|c|c|c|}
\hline \multicolumn{4}{|c|}{ Survey sample } \\
\hline No. & $\begin{array}{c}\text { Number of } \\
\text { buildings }\end{array}$ & $\%$ & $\begin{array}{c}\text { Number of } \\
\text { storeys }\end{array}$ \\
\hline & & & \\
\hline 1 & 1 & $2.4 \%$ & 2 \\
2 & 12 & $29.3 \%$ & 3 \\
3 & 9 & $22.0 \%$ & 4 \\
4 & 6 & $14.6 \%$ & 5 \\
5 & 3 & $7 \cdot 3 \%$ & 6 \\
6 & 1 & $2.4 \%$ & 7 \\
7 & 1 & $2.4 \%$ & 8 \\
8 & 5 & $12.2 \%$ & 9 \\
9 & 1 & $2.4 \%$ & 11 \\
10 & 2 & $4.9 \%$ & 12 \\
\hline
\end{tabular}

Source: Kozik and Zima, 2007, 2008.

Table 1. Distribution of buildings grouped according to the number of the above-ground storeys

As Table 1 reveals, in the analysed period of time the greatest number of new buildings included those with 3 and 4 storeys. Those with 5 and 9 storeys constitute several percent of new buildings. Other buildings make up a few percent of all new constructions. The characteristic features of the analysed multi-family buildings can provides information about the basic material from which walls (W) and ceilings (C) were designed.

be found in Table 2. The table also

\begin{tabular}{|c|c|c|c|c|c|c|c|c|}
\hline \multirow{3}{*}{ No. } & \multirow{2}{*}{$w$} & \multirow{2}{*}{ C } & VM & NoS & $A B$ & UA & AS & $\mathbf{L}$ \\
\hline & & & {$\left[\mathrm{m}^{3}\right]$} & [items] & {$\left[\mathrm{m}^{2}\right]$} & {$\left[\mathrm{m}^{2}\right]$} & {$\left[\mathrm{m}^{2}\right]$} & [m] \\
\hline & 1 & 2 & 3 & 4 & 5 & 7 & 9 & 10 \\
\hline 1 & MAX & $M$ & 1307.4 & 2 & 211.3 & 282.5 & 772.0 & 75.4 \\
\hline 2 & $P$ & $M$ & 6850.4 & 3 & 626.5 & 1325.2 & 904.0 & 160.0 \\
\hline 3 & $P$ & $M$ & 1524.5 & 3 & 276.2 & 559.4 & 745.0 & 60.0 \\
\hline 4 & $\mathrm{~S}$ & $\mathrm{~F}$ & 5509.3 & 3 & 650.0 & 2065.7 & 2317.3 & 118.3 \\
\hline 5 & $\mathrm{~S}$ & $\mathrm{~F}$ & 5509.3 & 3 & 650.0 & 2065.7 & 2317.3 & 118.3 \\
\hline 6 & $S$ & $\mathrm{~F}$ & 5509.3 & 3 & 650.0 & 2065.7 & 2317.3 & 118.3 \\
\hline 7 & $S$ & $\mathrm{~F}$ & 5509.3 & 3 & 650.0 & 2065.7 & 2317.3 & 118.3 \\
\hline 8 & $\mathrm{Ce}$ & M & 8925.0 & 3 & 615.5 & 1968.8 & 2215.0 & 140.0 \\
\hline 9 & $\mathrm{Ce}$ & $M$ & 8044.4 & 3 & 619.5 & 1774.5 & 2215.0 & 140.0 \\
\hline 10 & $P$ & $M$ & 8471.4 & 3 & 1154.6 & 2398.9 & 3790.0 & 153.2 \\
\hline 11 & $\mathrm{P}$ & $M$ & 8471.4 & 3 & 1154.6 & 2398.9 & 3790.0 & 153.2 \\
\hline 12 & MAX & $\mathrm{F}$ & 10416.0 & 3 & 1195.5 & 2468.0 & 6424.5 & 195.0 \\
\hline 13 & MAX & $\mathrm{F}$ & 10351.0 & 3 & 1195.5 & 2462.9 & 6424.5 & 192.0 \\
\hline 14 & $P$ & $M$ & 5017.7 & 4 & 540.0 & 1533.4 & 2440.0 & 142.0 \\
\hline 15 & $P$ & $M$ & 5606.0 & 4 & 374.0 & 1161.0 & 894.0 & 120.0 \\
\hline 16 & $\mathrm{P}$ & $M$ & 14514.0 & 4 & 1220.1 & 3074.6 & 4159.0 & 156.6 \\
\hline 17 & $P$ & $M$ & 1687.0 & 4 & 198.5 & 530.3 & 787.0 & 76.9 \\
\hline 18 & MAX & $M$ & 13727.0 & 4 & 1001.6 & 3650.5 & 3942.0 & 141.9 \\
\hline 19 & $\mathrm{~S}$ & M & 3150.0 & 4 & 244.4 & 710.5 & 670.0 & 63.9 \\
\hline 20 & $S$ & $M$ & 10133.2 & 4 & 896.5 & 2857.3 & 3862.0 & $159 \cdot 5$ \\
\hline 21 & $\mathrm{~K}_{3}$ & $M$ & 13396.5 & 4 & 1109.5 & 3275.2 & 6336.0 & 200.0 \\
\hline 22 & $\mathrm{Ce}$ & $M$ & 12396.4 & 4 & 800.0 & 2734.5 & 4950.0 & 180.0 \\
\hline 23 & $\mathrm{P}$ & $M$ & 6451.0 & 5 & 586.5 & 1994.0 & 4136.0 & 155.0 \\
\hline 24 & $\mathrm{Ce}$ & $M$ & 10927.6 & 5 & 629.0 & 2410.5 & 2215.0 & 150.0 \\
\hline 25 & $\mathrm{~S}$ & $M$ & 25903.8 & 5 & 1442.1 & 7359.0 & 6452.0 & 242.8 \\
\hline 26 & $P$ & M & 11427.0 & 5 & 842.6 & 3213.3 & 5200.0 & 162.5 \\
\hline 27 & $P$ & M & 10686.0 & 5 & 787.2 & 2977.5 & 4920.0 & 166.2 \\
\hline 28 & $P$ & $M$ & 2325.0 & 5 & 155.0 & 1058.9 & 485.0 & 49.8 \\
\hline 29 & $\mathrm{~S}$ & $M$ & 24670.0 & 6 & 1106.0 & 6272.5 & 5041.0 & 168.0 \\
\hline 30 & $\mathrm{Ce}$ & $M$ & 31000.0 & 6 & 1090.2 & 5726.0 & 8860.0 & 183.5 \\
\hline 31 & $\mathrm{~S}$ & $M$ & 27050.0 & 7 & 1106.0 & 6880.5 & 5041.0 & 183.5 \\
\hline 32 & FC & $\mathrm{F}$ & 33765.9 & 8 & 1075.0 & 8548.4 & 3707.0 & 217.6 \\
\hline 33 & $\mathrm{~K}_{3}$ & $M$ & 51266.2 & 9 & 2544.7 & 11457.0 & 9606.0 & 210.9 \\
\hline 34 & $P$ & $M$ & 14361.4 & 9 & 582.9 & 4230.1 & 2318.4 & 107.6 \\
\hline 35 & $P$ & $M$ & 31331.2 & 9 & 1184.5 & 8689.2 & 4636.9 & 184.2 \\
\hline 36 & $P$ & $M$ & 27516.4 & 9 & 1113.8 & 8141.0 & 4636.9 & 184.2 \\
\hline 37 & $P$ & $M$ & 14361.4 & 9 & 582.9 & 4230.1 & 2318.4 & 107.6 \\
\hline 38 & $P$ & $M$ & 34790.0 & 11 & 2079.7 & 9938.4 & 12495.0 & 223.0 \\
\hline 39 & $P$ & $M$ & 23150.0 & 12 & 519.5 & 6196.7 & 6657.6 & 104.9 \\
\hline 40 & $P$ & $M$ & 24680.0 & 12 & 562.5 & 6680.7 & 6700.0 & 111.5 \\
\hline
\end{tabular}




\begin{tabular}{|c|c|}
\hline VM - volume & C - ceilings \\
\hline measure & $\mathrm{Ce}-$ ceramics \\
\hline $\mathrm{L}$ - perimeter & $A B-$ area of \\
\hline $\mathrm{K}_{3}-\mathrm{K}_{3}$ brick & building site \\
\hline $\begin{array}{c}\text { NoS - number of } \\
\text { storeys }\end{array}$ & $\begin{array}{l}\text { S - silikat } \\
\text { FC - ferroconcrete }\end{array}$ \\
\hline W - walls & UA - usable area \\
\hline MAX - air-brick & $\mathrm{P}$ - porotherm \\
\hline $\operatorname{MAX}$ & F- filigree \\
\hline AS - area surface & M-monolithic \\
\hline
\end{tabular}

Table 2 shows that the most popular materials for vertical partitions in the analysed period of time were breeze-blocks Porotherm (47.5\%), silikats (22.5\%), ceramics (12.5\%) and the MAX air-bricks (10.0\%). Ceilings were mostly monolithic (82.5\%) and filigree panels (17.5\%) which allow to form rooms freely as there is no need to use supporting ribs under walls and partition walls, like in the case of suspended beam and block floor. The analysed buildings have the volume measure from $1000 \mathrm{~m} 2$ to over 50000 m2. Buildings of $600 \mathrm{~m} 2,600-1000$ $\mathrm{m} 2$ and $1000-2$ ooo m2 constitute about $30 \%$ of the analysed constructions. Buildings with the surface bigger than 2 ooom 2 make up no more than $5 \%$.

Table 3 shows the distribution of the values of some chosen indexes evaluating the complexity of building shape.

In Table 3 the numbers in bold are those coefficients which are considered the most advantageous. For W/F index these are the values of up to 1.00 found only in 2 buildings. The $\mathrm{LBI}$ index of up to 2.00 value is considered advantageous and characterizes only 3 buildings. Also 3 buildings have the advantageous $J C$ index of the value up to 0.10. The most advantageous values of the POP index are those between 0.80 and 1.00 , possessed by 5 buildings. Almost $60 \%$ (58.54\%) of the analysed buildings have the $m$ index greater than 5 which indicates a considerably high degree of shape complexity, as well as high costs of construction and later use. Only $9.76 \%$ of the buildings has the

\begin{tabular}{|c|c|c|c|c|c|c|}
\hline Lp & $W / F$ & LBI & $\mathrm{JC}$ & POP & m & VOLM \\
\hline best value & 0 & 1 & 0 & 1 & 4 & 3.84 \\
\hline 1 & 1.17 & $4 \cdot 50$ & 0.30 & 0.68 & 5.19 & 2.17 \\
\hline 2 & 2.16 & 8.09 & 0.60 & 0.55 & 6.39 & 2.21 \\
\hline 3 & 1.27 & 3.90 & 0.24 & 0.71 & 4.96 & 1.84 \\
\hline 4 & 1.72 & 3.06 & 0.16 & 0.76 & 4.64 & 1.84 \\
\hline 5 & 1.72 & 3.06 & 0.16 & 0.76 & 4.64 & 1.84 \\
\hline 6 & 1.72 & 3.06 & 0.16 & 0.76 & 4.64 & 1.84 \\
\hline 7 & 1.72 & 3.06 & 0.16 & 0.76 & 4.64 & 1.84 \\
\hline 8 & 1.96 & 5.79 & 0.41 & 0.63 & 5.64 & 2.68 \\
\hline 9 & 1.96 & $5 \cdot 74$ & 0.41 & 0.63 & 5.62 & 2.49 \\
\hline 10 & 2.09 & 2.71 & 0.13 & 0.79 & $4 \cdot 51$ & 1.38 \\
\hline 11 & 2.09 & 2.71 & 0.13 & 0.79 & $4 \cdot 51$ & 1.38 \\
\hline 12 & 2.49 & 5.78 & 0.41 & 0.63 & 5.64 & 1.53 \\
\hline 13 & 2.46 & $5 \cdot 53$ & 0.39 & 0.64 & $5 \cdot 55$ & 1.52 \\
\hline 14 & 1.98 & 7.20 & 0.53 & 0.58 & 6.11 & 2.08 \\
\hline 15 & 1.74 & 7.49 & 0.55 & 0.57 & 6.21 & 3.24 \\
\hline 16 & 2.13 & 2.65 & 0.12 & 0.79 & $4 \cdot 48$ & 1.87 \\
\hline 17 & 1.19 & 5.26 & 0.36 & 0.65 & 5.46 & 2.74 \\
\hline 18 & 1.98 & 2.65 & 0.12 & 0.79 & 4.48 & 2.20 \\
\hline 19 & 1.00 & 1.52 & 0.02 & 0.87 & 4.09 & $3 \cdot 37$ \\
\hline 20 & 2.16 & 4.89 & 0.33 & 0.67 & 5.33 & 2.00 \\
\hline 21 & 2.54 & 6.87 & 0.50 & 0.59 & 6.00 & 1.95 \\
\hline 22 & 2.35 & 8.00 & 0.59 & 0.56 & 6.36 & 2.57 \\
\hline 23 & 2.11 & 8.12 & 0.60 & 0.55 & 6.40 & 2.27 \\
\hline 24 & 2.06 & 6.80 & 0.50 & 0.59 & 5.98 & 3.00 \\
\hline 25 & 2.90 & 8.10 & 0.60 & 0.55 & 6.39 & 2.33 \\
\hline 26 & 2.19 & 5.66 & 0.40 & 0.63 & 5.60 & 2.31 \\
\hline 27 & 2.22 & 6.62 & 0.48 & 0.60 & 5.92 & 2.37 \\
\hline 28 & 0.76 & 1.01 & 0.00 & 0.89 & 4.00 & $4 \cdot 35$ \\
\hline 29 & 2.24 & 4.14 & 0.26 & 0.70 & 5.05 & 2.94 \\
\hline 30 & 2.39 & $5 \cdot 54$ & 0.39 & 0.64 & 5.56 & 3.47 \\
\hline 31 & 2.39 & 5.43 & 0.38 & 0.64 & $5 \cdot 52$ & 3.13 \\
\hline 32 & 2.69 & 8.90 & 0.66 & 0.53 & 6.64 & 3.73 \\
\hline 33 & 2.63 & 1.82 & 0.05 & 0.85 & 4.18 & 2.08 \\
\hline 34 & 1.59 & 2.58 & 0.11 & 0.80 & 4.46 & 3.89 \\
\hline 35 & 2.39 & 4.96 & 0.34 & 0.66 & $5 \cdot 35$ & 3.22 \\
\hline 36 & 2.39 & 5.43 & 0.38 & 0.64 & $5 \cdot 52$ & 3.14 \\
\hline 37 & 1.59 & 2.58 & 0.11 & 0.90 & 4.46 & 3.89 \\
\hline 38 & 2.73 & 3.71 & 0.22 & 0.72 & 4.89 & 1.97 \\
\hline 39 & 1.56 & 2.96 & 0.15 & 0.77 & 4.60 & 6.00 \\
\hline 40 & 1.64 & 3.21 & 0.18 & 0.75 & $4 \cdot 70$ & 5.78 \\
\hline
\end{tabular}

Source: author's own data

Table 3. Coefficients evaluating the shape of the buildings with building permits issued in 2004-2005

shape which can be considered ideal. The analysis of the VOLM index whose values of 3.50-4.00 indicate minimal complexity of the building block reveals that only $7.32 \%$ of the buildings can be thought as possessing a simple shape. Yet none of the buildings considered simple according to the surface criterion cannot be thought as such according to the VOLM index. 


\section{Description of the investments with building permits issued in 2010}

The next analysis concerned 30 multifamily buildings constructed in Krakow which received building permits in the second half of the year 2010 . The distribution of the survey sample grouped according to the number of the above-ground storeys is presented in Table 4. The characteristic features of the studied multi-family buildings are shown in Table 5 .

\begin{tabular}{|c|c|c|c|}
\hline \multicolumn{4}{|c|}{ Survey sample } \\
\hline No. & $\begin{array}{c}\text { No. of } \\
\text { buildings }\end{array}$ & $\%$ & $\begin{array}{c}\text { No. of } \\
\text { storeys }\end{array}$ \\
\hline 1 & 0 & $0.00 \%$ & 2 \\
\hline 2 & 4 & $13.33 \%$ & 3 \\
\hline 3 & 8 & $26.67 \%$ & 4 \\
4 & 7 & $23.33 \%$ & 5 \\
5 & 5 & $16.67 \%$ & 6 \\
6 & 3 & $10.00 \%$ & 7 \\
7 & 1 & $3 \cdot 33 \%$ & 8 \\
8 & 1 & $3.33 \%$ & 9 \\
9 & 0 & $0.00 \%$ & 11 \\
10 & 1 & $3.33 \%$ & 12 \\
\hline
\end{tabular}

Source: author's analysis of the data from the Office of the City of Krakow, Faculty of Architecture and Urban Planning

Table 4. Distribution of buildings grouped according to the number of the above-ground storeys

Materials most frequently used for vertical partitions are breeze blocks Porotherm (33.3\%), poured concrete monolithic walls (30\%) and Ytong blocks (26.7\%). Ceilings are largely monolithic $(96.6 \%$, in one case there was no data). The other data in Table 5 describing the buildings under construction are the surface and cubic coefficients.

Table 6 reveals the distribution of the values of some chosen indexes evaluating the degree of building shape complexity.

Only one building has the advantageous value of the W/F index. 4 buildings are marked by the LBI index also considered advantageous and 7 by

\begin{tabular}{|c|c|c|c|c|c|c|c|c|}
\hline \multirow{3}{*}{ No. } & \multirow{2}{*}{$\mathbf{W}$} & \multirow{2}{*}{ C } & VM & Nos & $A B$ & UA & AS & $\mathbf{L}$ \\
\hline & & & {$\left[\mathrm{m}^{3}\right]$} & [szt.] & {$\left[\mathrm{m}^{2}\right]$} & {$\left[\mathrm{m}^{2}\right]$} & {$\left[\mathrm{m}^{2}\right]$} & [m] \\
\hline & 1 & 2 & 3 & 4 & 5 & 7 & 9 & 10 \\
\hline 1 & $S$ & $M$ & 10442.9 & $5(6)$ & 499.3 & 2658.7 & 1365.0 & 126.8 \\
\hline 2 & nd & nd & nd & $4(5)$ & 314.6 & 1132.6 & 1049.0 & 71.9 \\
\hline 3 & M & M & 25449.7 & $11(12)$ & 828.2 & 5055.1 & 3229.3 & 146.2 \\
\hline 4 & $P$ & $M$ & 3355.7 & $5(7)$ & 783.2 & 348.3 & 1410.2 & 123.5 \\
\hline 5 & $\mathrm{P}$ & M & 4311.0 & $5(7)$ & 625.5 & 575.8 & 1410.2 & 118.4 \\
\hline 6 & $P$ & M & 4168.2 & $5(7)$ & 611.2 & 512.2 & 1410.2 & 118.4 \\
\hline 7 & $P$ & $M$ & 37883.0 & 9(11) & 1289.5 & 10577.6 & 2882.0 & 218.5 \\
\hline 8 & M & M & 28140.3 & $7(8)$ & 943.2 & 6613.2 & 2893.8 & 144.9 \\
\hline 9 & $M$ & $M$ & 25115.4 & $7(8)$ & 841.7 & 5902.3 & 2893.8 & 133.8 \\
\hline 10 & $Y$ & $M$ & 5257.2 & 4(5) & $445 \cdot 3$ & nd & 7158.0 & 92.6 \\
\hline 11 & $Y$ & M & 5675.2 & 4(5) & 469.1 & nd & 7158.0 & 91.1 \\
\hline 12 & $Y$ & $M$ & 8393.0 & 4(5) & 520.4 & nd & 2808.8 & 102.7 \\
\hline 13 & $Y$ & $M$ & 10273.0 & 4(5) & 611.3 & nd & 3299.8 & 128.9 \\
\hline 14 & $Y$ & M & 8089.0 & $3(4)$ & 560.7 & nd & 3026.4 & 111.1 \\
\hline 15 & Y & $M$ & 8650.0 & $3(4)$ & 564.2 & nd & 3045.0 & 121.3 \\
\hline 16 & $Y$ & $M$ & 5551.0 & $3(4)$ & 395.8 & nd & 2135.9 & 86.9 \\
\hline 17 & M & M & 8643.3 & $6(7)$ & 464.1 & 2376.1 & 5829.0 & 91.1 \\
\hline 18 & $M$ & $M$ & 4339.7 & $6(7)$ & 1850.1 & 8299.3 & nd & 295.2 \\
\hline 19 & $M$ & $M$ & 4410.3 & 8(9) & 1702.1 & 8432.2 & nd & 210.1 \\
\hline 20 & M & $M$ & 2411.5 & $6(7)$ & 1039.1 & 4471.8 & nd & 160.0 \\
\hline 21 & M & $M$ & 2141.7 & $6(7)$ & 923.0 & 3893.0 & nd & 151.0 \\
\hline 22 & $\mathrm{P}$ & M & 11197.3 & $5(6)$ & 761.8 & 3532.4 & 1406.1 & 156.8 \\
\hline 23 & $P$ & $M$ & 4392.9 & 4 & 305.7 & 1320.0 & 3662.0 & 114.8 \\
\hline 24 & $P$ & $M$ & 13483.4 & $5(6)$ & 856.6 & 3394.6 & 2528.8 & 189.4 \\
\hline 25 & $\mathrm{P}$ & M & 13532.5 & $5(6)$ & 859.8 & 3411.9 & 2538.0 & 190.1 \\
\hline 26 & $P$ & M & 10235.1 & 4(5) & 803.4 & 2528.2 & 2371.6 & 186.3 \\
\hline 27 & $P$ & M & 10912.7 & 4(5) & 856.6 & 2712.7 & 2528.6 & $187 \cdot 3$ \\
\hline 28 & $Y$ & $M$ & 760.0 & 3(3) & 123.0 & 165.1 & 910.0 & 47.0 \\
\hline 29 & M & M & nd & $6(7)$ & 501.8 & 235.9 & 1890.0 & 106.5 \\
\hline 30 & H & $M$ & nd & $7(7)$ & 482.7 & nd & 1672.3 & 107.6 \\
\hline$V M-v$ & lume & easu & & $L-p e$ & eter & & $\mathrm{P}-$ poro & \\
\hline $\begin{array}{l}\text { NoS - } \\
\text { storey } \\
\text { storey } \\
\text { AS - a }\end{array}$ & $\begin{array}{l}\text { umbe } \\
\text { (abov }\end{array}$ & & $\begin{array}{l}\text { e-ground } \\
\text { ground }\end{array}$ & $\begin{array}{l}A B- \\
U A- \\
W- \\
C-c E\end{array}$ & $\begin{array}{l}\text { ea of build } \\
\text { able area } \\
\text { ls } \\
\text { ng }\end{array}$ & g site & $\begin{array}{c}\mathrm{S}-\text { silika } \\
\mathrm{Y}-\text { Ytong } \\
\mathrm{H}-\mathrm{H}+\mathrm{H} \\
\mathrm{M}-\text { mono }\end{array}$ & $\begin{array}{l}\text { locks } \\
\text { ocks } \\
\text { hic }\end{array}$ \\
\hline
\end{tabular}

nd - no data

Source: author's analysis of the data from the Office of the City of Krakow, Faculty of

Architecture and Urban Planning

Table 5. Data describing multi-family buildings constructed in Krakow (building permits in 2010)

the JC and POP. Precisely $43.33 \%$ of the analysed buildings has the coefficient value greater than 5 . Only $13.33 \%$ has the shape which can be considered very good. As far as the VOLM index is concerned, assuming the same range of complexity as before, i.e. values between 3.50 and 4.00 indicating a building block as simple, only $11.11 \%$ of the analysed buildings can be thought to have a simple shape. As previously, none of the buildings considered simple according to the surface criterion possesses a simple shape when analysed according to the VOLM index.

Figures $1 \mathrm{a}, 1 \mathrm{~b}, 1 \mathrm{c}$ depict the influence of the change in the building shape and, consequently, the change in the factors evaluating building shape and construction costs, as shown in Table 5 . 


\begin{tabular}{|c|c|c|c|c|c|c|}
\hline Ip & $W / F$ & LBI & JC & POP & $\mathrm{m}$ & VOLM \\
\hline best value & 0 & 1 & 0 & 1 & 4 & \\
\hline 1 & 1.81 & 5.88 & 0.42 & 0.62 & 5.67 & 3.67 \\
\hline 2 & 1.12 & 1.38 & 0.01 & 0.88 & 4.05 & nd \\
\hline 3 & 2.02 & 4.22 & 0.27 & 0.70 & 5.08 & 4.01 \\
\hline 4 & 1.78 & 2.46 & 0.10 & 0.80 & 4.41 & 1.10 \\
\hline 5 & 1.72 & 3.30 & 0.18 & 0.75 & $4 \cdot 74$ & 1.63 \\
\hline 6 & 1.72 & 3.45 & 0.20 & 0.74 & $4 \cdot 79$ & 1.63 \\
\hline 7 & 2.70 & 7.11 & 0.52 & 0.58 & 6.08 & 3.36 \\
\hline 8 & 2.01 & 3.25 & 0.18 & 0.75 & 4.72 & 3.77 \\
\hline 9 & 1.89 & 2.98 & 0.15 & 0.77 & 4.61 & 3.91 \\
\hline 10 & 1.41 & 2.39 & 0.10 & 0.81 & 4.39 & 2.61 \\
\hline 11 & 1.39 & 1.89 & 0.05 & 0.84 & 4.20 & 2.60 \\
\hline 12 & 1.53 & 2.69 & 0.13 & 0.79 & 4.50 & 3.05 \\
\hline 13 & 1.84 & 4.58 & 0.30 & 0.68 & 5.21 & 2.97 \\
\hline 14 & 1.64 & 3.19 & 0.17 & 0.76 & 4.69 & 2.76 \\
\hline 15 & 1.75 & 4.29 & 0.28 & 0.69 & 5.11 & 2.87 \\
\hline 16 & 1.33 & 2.35 & 0.09 & 0.81 & $4 \cdot 37$ & 3.04 \\
\hline 17 & 1.39 & 1.96 & 0.06 & 0.84 & 4.23 & 3.48 \\
\hline 18 & $3 \cdot 30$ & 9.67 & 0.72 & 0.52 & 6.86 & 0.55 \\
\hline 19 & 2.62 & 4.25 & 0.27 & 0.70 & 5.09 & 0.61 \\
\hline 20 & 2.16 & 3.90 & 0.24 & 0.71 & 4.96 & 0.66 \\
\hline 21 & 2.07 & 3.92 & 0.24 & 0.71 & 4.97 & 0.69 \\
\hline 22 & 2.13 & 5.90 & 0.42 & 0.62 & 5.68 & 2.52 \\
\hline 23 & 1.68 & 8.67 & 0.64 & 0.54 & 6.57 & $3 \cdot 37$ \\
\hline 24 & 2.44 & 8.35 & 0.62 & 0.55 & 6.47 & 2.54 \\
\hline 25 & 2.45 & 8.39 & 0.62 & 0.55 & 6.48 & 2.54 \\
\hline 26 & 2.41 & 8.69 & 0.64 & 0.54 & 6.57 & 2.25 \\
\hline 27 & 2.42 & 8.12 & 0.60 & 0.55 & 6.40 & 2.20 \\
\hline 28 & 0.71 & 1.99 & 0.06 & 0.84 & 4.24 & 2.60 \\
\hline 29 & 1.58 & 3.35 & 0.19 & 0.75 & $4 \cdot 76$ & nd \\
\hline 30 & 1.59 & 3.72 & 0.22 & 0.72 & 4.90 & nd \\
\hline
\end{tabular}

Source: author's own data

Table 6. Coefficients evaluating the shapes of the buildings for which permits were granted in 2010

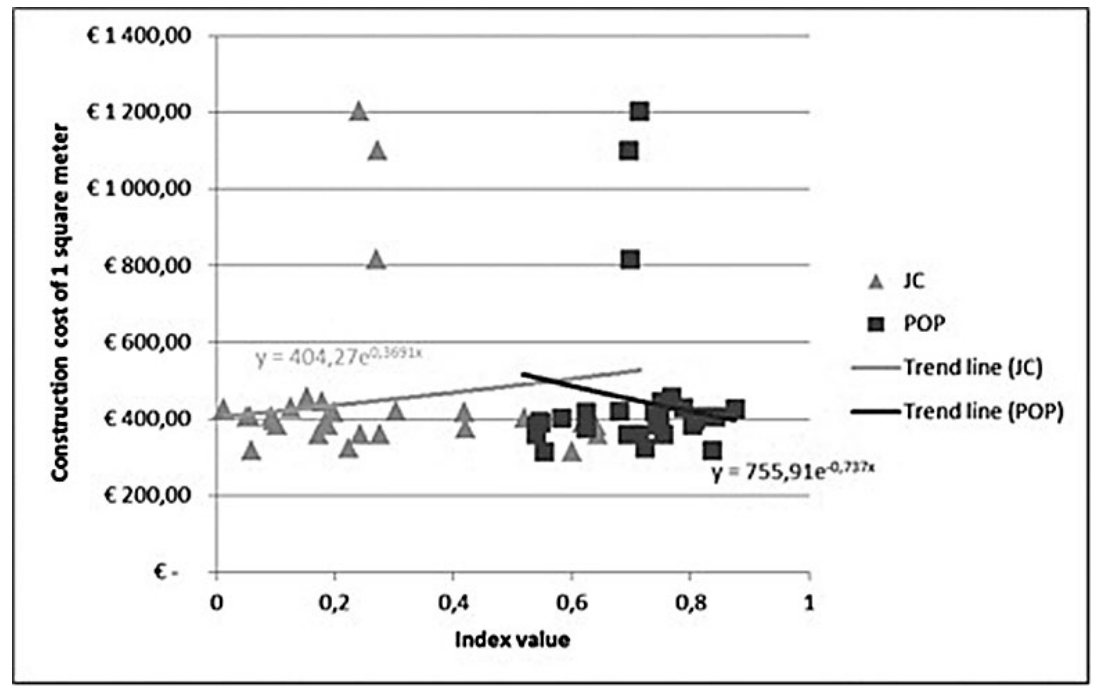

Figure 1a. The relationship between construction costs of the analysed buildings and the JC and POP factors evaluating building shape.

The construction costs of individual buildings presented in Table 5 were calculated in the investors' cost estimates by means of a simplified technique. Having compared the construction costs of $1 \mathrm{~m}^{2}$ and the building shape factors presented in Table 6 , one observes a tendency in the building shape changes depending on the changes of individual factors. Thus altering the values of the JC and POP by 0.1 (e.g. from 0.3 to 0.4 ) changes construction costs to $3.8 \%$ and $7.6 \%$ respectively (Figure $1 \mathrm{a}$ ). In the case of the $\mathrm{m}, \mathrm{LBI}$ and $\mathrm{W} / \mathrm{F}$, altering one of these factors by 1 causes the growth in costs by $0.9 \%, 3.3 \%$ and $4.4 \%$ (Figure $1 \mathrm{~b})$. Finally, altering the VOLM factor by 0.5 increases construction costs by $4.4 \%$.

\section{The intensity of built-up areas}

Evaluation of the way a building site was used can be conducted as an index of intensity of built-up areas. It is understood as an index specifying the relationship of the total building site area on a certain location to the size of the land of that location. For Polish norm PN ISO 9836 total building site area is defined as the area taken up by the completed building and is specified by a vertical drop of the outer edges of the building on the area surface.

The area of a building site does not include the following:

the surface of buildings or their parts situated below the ground;

- the surface of secondary elements, such as outer stairs, outer ramps, canopies, awnings, roof protrusions or outer lighting;

- the surface taken up by auxiliary buildings, e.g. greenhouses, gazeboes, or sheds.

As an intensity of built-up areas index $I$ let us assume the relation between the building site area $P_{z}$ and the area of the plot $P_{t}$. When analysing how the area in Krakow has been used for 


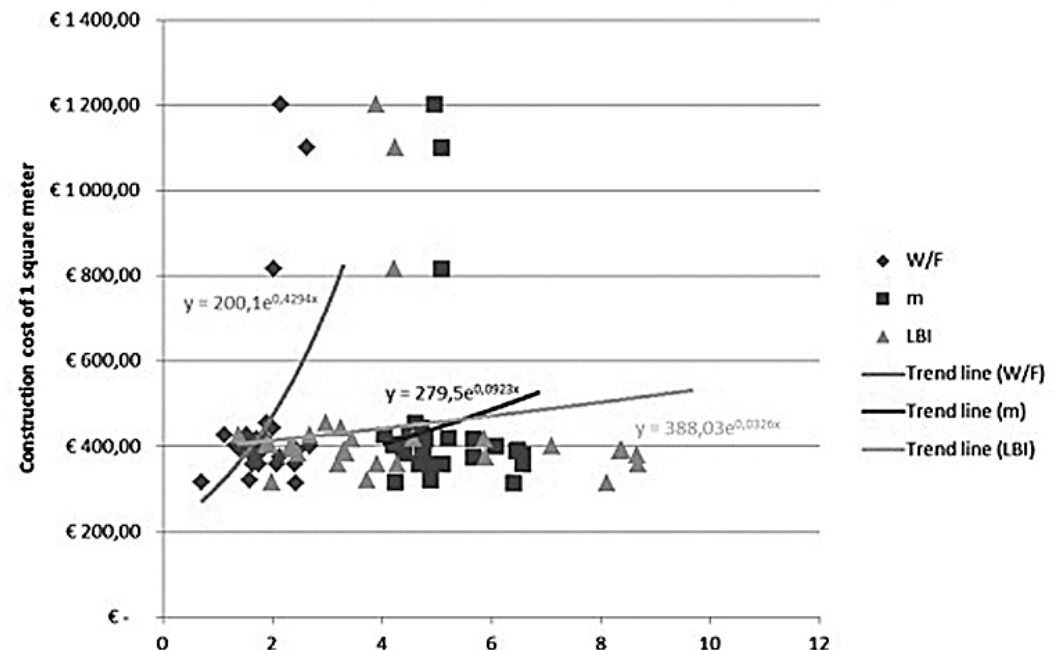

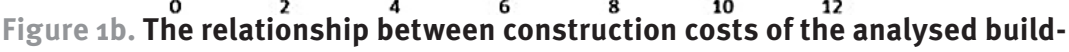
ings and the $\mathrm{m}, \mathrm{LB}$ and $\mathrm{W} / \mathrm{F}$ factors evaluating building shape.

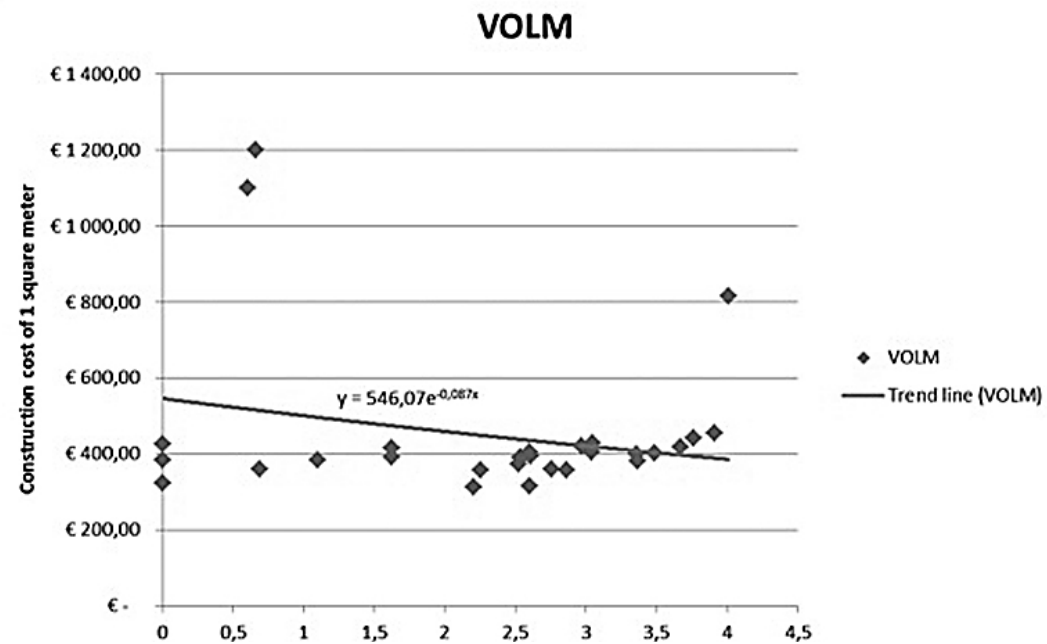

Figure 1C. The relationship between construction costs of the analysed buildings and the VOLM factor evaluating building shape.

\begin{tabular}{|c|c|c|c|c|c|c|c|c|}
\hline No. & 2010 & 2004 & No. & 2010 & 2004 & No. & 2010 & 2004 \\
\hline 1 & $8.3 \%$ & $27.4 \%$ & 15 & $54.2 \%$ & $41.8 \%$ & 29 & nd & $21.9 \%$ \\
\hline 2 & $25.6 \%$ & $69.3 \%$ & 16 & $33.9 \%$ & $29.3 \%$ & 30 & $44.7 \%$ & $24.4 \%$ \\
\hline 3 & $13.5 \%$ & $37.1 \%$ & 17 & $33.9 \%$ & $25.2 \%$ & 31 & - & $12.3 \%$ \\
\hline 4 & $18.5 \%$ & $28.0 \%$ & 18 & $55.5 \%$ & $25.4 \%$ & 32 & - & $21.9 \%$ \\
\hline 5 & $18.5 \%$ & $28.0 \%$ & 19 & $44.4 \%$ & $36.5 \%$ & 33 & - & $29.0 \%$ \\
\hline 6 & $18.5 \%$ & $28.0 \%$ & 20 & $43.3 \%$ & $23.2 \%$ & 34 & - & $26.5 \%$ \\
\hline 7 & $30.0 \%$ & $28.0 \%$ & 21 & $8.0 \%$ & $17.5 \%$ & 35 & - & $25.1 \%$ \\
\hline 8 & $6.2 \%$ & $27.8 \%$ & 22 & nd & $16.2 \%$ & 36 & - & $25.5 \%$ \\
\hline 9 & $6.6 \%$ & $28.0 \%$ & 23 & nd & $14.2 \%$ & 37 & - & $24.0 \%$ \\
\hline 10 & $18.5 \%$ & $30.5 \%$ & 24 & nd & $28.4 \%$ & 38 & - & $25.1 \%$ \\
\hline 11 & $18.5 \%$ & $30.5 \%$ & 25 & $26.6 \%$ & $22.4 \%$ & 39 & - & $16.6 \%$ \\
\hline 12 & $33.9 \%$ & $18.6 \%$ & 26 & $28.9 \%$ & $16.2 \%$ & 40 & - & $7.8 \%$ \\
\hline 13 & $33.9 \%$ & $18.6 \%$ & 27 & $32.6 \%$ & $16.0 \%$ & 41 & - & $84 \%$ \\
\hline 14 & $36.6 \%$ & $22.1 \%$ & 28 & $29.1 \%$ & $32.0 \%$ & average & $27.8 \%$ & $25.2 \%$ \\
\hline
\end{tabular}

Source: author's analysis of the data from the Office of the City of Krakow, Faculty of Architecture and Urban Planning

Table 7. The intensity of built-up areas index for multi-family building investments in Krakow building investments one notices a small increase in its use. The average intensity of built-up areas in the case of buildings for which permits were given in 2010 was $27.8 \%$, while the percentage in $2004-2005$ was $25.2 \%$ (Table 7).

The intensity of built-up areas index ranged between $6.2 \%$ and $55.5 \%$ in the case of buildings with building permit granted in 2010, and between $7.8 \%$ and $69.3 \%$ for buildings with the permit issued in 2004-2005. One notices a tendency to increase the use of the building site, probably due to the smaller number of available plots in Krakow, the growing competition on the building market and high prices of estates.

\section{Conclusions}

Analysing the change in the shape of the buildings constructed in Krakow in the years 2004/2005 and in 2010, a certain improvement can be noticed. Slightly more 2010 buildings have the most advantageous values of the LBI, JC and POP factors. The noticeable tendency is specified by the $m$ index for buildings with the 2004-2005 permit equal to 5.48 ( $58.54 \%$ of very complex shapes) and for newer buildings with the 2010 permit 5.16 (43.33\% of complex shapes). This gradual improvement in the compactness of the building block is shown by the VOLM index.

A slow growth in the use of plots for building investments in Krakow is noticeable, which is caused by the increasing experience of designers, who are "forced" by investors to maximize the profits from the use of the plot. The average intensity of built-up areas in the case of buildings with the 2010

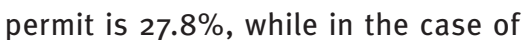
the buildings with the 2004/2005 permit $-25.2 \%$. The intensity index ranged between $6.2 \%-55.5 \%$ in the case of the buildings with the 2010 
permit, and $7.8 \%-69.3 \%$ in the case of the buildings with the 2004/2005 permit.

What is even more noticeable is designing buildings having costs in mind, which translates into constructing buildings simpler in shape to decrease the costs of construction. Clients' preferences as well as legal requirements, i.e. the obligation of preparing energy certificates for buildings, which has been in force since January 2009, cause greater care for possible loss of heat.

\section{References}

[1] Ashworth, A. (2004), Cost studies of buildings, Trans-Atlantic Pubns, 4 th ed.

[2] Brandon, P.S. (1978), “A framework for cost exploration and strategic cost planning in design", Chartered Surveyor Building and Quantity Surveying Quarterly, 5(4), pp. 60-63.
[3] Ferry, D.J. and Brandon P.S. (2007), Cost planning of building, Wiley-Blackwell, Oxford, 8th ed.

[4] Karshenas, S. (1984), “Predesign cost estimating method for multistory buildings", Journal of Construction Engineering and Management, 110(1), pp. 79-86.

[5] Kouskoulas, V. and Koehn, E. (1974), "Predesign cost-estimation function for buildings", Journal of the Construction Division, ASCE, 100(CO4), pp. 589-604.

[6] Kozik, R. and Zima, K. (2007), “Analysis of housing investments realized by developers", Scientific Papers of Gdansk University of Technology, No. 605, Land Engineering No. LXI, Gdańsk, pp. 23-30 (in polish).

[7] Kozik, R. and Zima, K. (2008), "Analysis and evaluation of developer projects" in 15th Annual European Real Estate Society Conference, ERES, UE in Krakow, Book of Abstracts, Krakow 8-21, pp. 76.

[8] Selley, L.H. (1983), Building Economics, Macmillan, London, 3rd ed.

[9] Sonmez, R. (2004), “Conceptual cost estimation of building projects with regression analysis and neural networks", Canadian Journal of Civil Engineering, No. 31, pp. 677-683.

[10] Staedman, P., Evans, S. and Batty, M. (2009), "Wall area, volume and plan depth in the building stock", Building Research \& Information, 37: 5, pp. 455-467.

[11] Swaffield, L.M. and Pasquire, C.L. (1996), “A critique of mechanical and electrical services cost planning: existing methods and published information", Journal of Financial Management of Property and Construction, 1(3), pp. 23-41. [12] Wing, C.K. (1999), "On the issue of plan shape complexity: plan shape indices revisited", Construction Management and Economic, No 17, pp. 473-482.

[13] Zima, K. (2008), "Influence of building shape on the construction cost", Scientific Papers of the Institute of Building Engineering of the Wroctaw University of Technology No. 91, series: Studies and Materials No. 20, Technology and management in construction, Wrocław, pp. 155-162 (in polish). 